\title{
Understanding the Determinants of Consumers' Willingness to Pay for Eco-Labeled Products: An Empirical Analysis of the China Environmental Label
}

\author{
Junyi Shen \\ Faculty of International Studies, Hiroshima City University, Hiroshima, Japan. \\ Email: shen@intl.hiroshima-cu.ac.jp \\ Received December $20^{\text {th }}, 2011$; revised January $4^{\text {th }}, 2012$; accepted January $15^{\text {th }}, 2012$
}

\begin{abstract}
This study applies data from a web-based survey conducted in mainland China to examine the determinants of consumers' willingness to pay (WTP) for seven different product categories awarded with China Environmental Label and compare the mean WTP estimates among these categories. The Interval Regression method is used for estimation. The results indicate that Chinese consumers who regard environmental conservation as being more important than life convenience, who believe purchasing the eco-labeled products is good for the environment, and who have the experience in purchasing eco-labeled products are willing to pay more for those products with environmental label or eco-label. In addition, socio-demographic characteristics such as gender, age, education and household income are found to be important factors to affect Chinese consumers' WTP amounts. Finally, the results of pair-wise comparison among the mean WTP estimates of various eco-labeled products indicate that most of them are different, which implies that the degrees of Chinese consumers' willingness to pay extra money for China Environmental Label are different based on the types of products.
\end{abstract}

Keywords: China Environmental Label; Eco-Labeled Products; Interval Regression; Payment Card; Willingness to Pay

\section{Introduction}

Environmental labels or eco-labels have been used for over twenty years to provide consumers information about a product which is characterized by improved environmental performance and efficiency compared with similar products. The main purpose of providing this kind of label is to avoid the asymmetric information problem between producers and consumers, because some environmentally friendly products normally have unobservable characteristics which will cause potential inefficiencies resulting from imperfect information [1]. There is enough evidence in the sense that a substantial part of environment problems have to do with the consumption of goods. On the other hand, it is obvious that once the goods are produced, designed and delivered into the market, there is not much that can be done to avoid environmental damage. Consumers' reactions are, consequently, crucial. In other words, because there is a need to influence the way goods are produced, changes in consumer behavior are important and eco-labels constitute a response [2].

Beginning with the German Blue Angel in 1977, a number of eco-labeling schemes in the organic food and electricity markets as well as the forestry products have been established in both developed and developing countries (e.g., Nordic Swan in the Nordic countries, EU Flower in EU countries, Energy Star in USA, Eco-Mark in Japan and India, Environmental Choice in Canada and New Zealand, Green Label in Singapore and Thailand, Environmental Label in China, etc.). Given that eco-labeling is not costless, certification and labeling programs may not achieve their objectives unless consumers are willing to pay for the underlying improvements in the production practices specified by the program [3]. In other words, the growing popularity of eco-labeled products is primarily based on the market-driven approach to achieving environmental goals. The increased concern of consumers for the environment and food safety, reflected by their willingness to pay relatively higher prices for products that has been produced in an environmentally friendly manner, provides a positive incentive for producers to choose techniques that minimize the adverse effects on the environment and improve the quality of final products [4]. 
There is strong evidence to suggest that consumers are willing to pay relatively higher price for various ecolabeled products [5-11], but little evidence to exhibit what determines the amount of consumers' willingness to pay (WTP). In particular, limited to our knowledge, there is almost no study in the literature examining and comparing the consumers' WTP among various kinds of ecolabeled products. However, under the consideration that consumers normally value variant types of products differently even they are with the same label, thus, in order to well understand the determinants of consumers' WTP for eco-labeled products, it is necessary to study different products with the same label. With respect to the issue of the determinants of consumers' WTP for eco-labeled products, economists and psychologists have developed a number of factors (e.g., consumers' environmental concern, perceived consumer effectiveness, faith in others, perceived compromise, and consumers' socio-demographic characteristics, etc.). Previous studies on these factors can be found in [12-15].

The current study uses contingent valuation (CV) techniques to investigate the determinants of consumers' WTP for seven product categories (i.e., furniture, appliance, building material, glass tableware, recycled paper, battery, and soft drink) awarded with China Environmental Label and compare the mean WTP estimates among these categories ${ }^{1}$. Note that these products are quite different in both their effect on the environment and price level. We conducted a web-based survey in which respondents were asked their hypothetical WTP for the above eco-labeled products through a payment card method $^{2}$. The WTP bids were provided by interval data (e.g., $6 \%-10 \%, 11 \%-20 \%, 21 \%-30 \%$, etc.). Thus, an Interval Regression model was applied in the empirical analysis (see detailed description in the next section). An alternative estimation method for interval data is midpoint estimation method ${ }^{3}$. However, the inherent presupposition of this method is that individual's expected WTP equals to the midpoint of the presented interval. If it is not the case, midpoint estimation method will lead to

\footnotetext{
${ }^{1}$ China Environmental Label was officially launched in 1994 by China Certification Committee for Environmental labeling Products (CCEL). CCEL, authorized by China State Bureau of Technology Supervision (CSBTS), is the third party certification agency representing the government to deal with environmental labeling certification as well as to administer and supervise the environmental labeling program in China. up to October 2007, more than 8000 products in at least 50 product categories have been awarded with the label.

${ }^{2}$ The payment card method was first developed by Mitchell and Carson in 1981 as an alternative to the bidding game. This method is sought to maintain the properties of the direct question by providing respondents with a visual aid which contains a large array of potential WTP amounts ranging from 0 to some large amount [16].

${ }^{3}$ The midpoint estimation approach refers to treating the midpoint of the presented interval as the WTP value and estimating by Ordinary Least Square (OLS).
}

significant biases in the estimates ${ }^{4}$.

As a preview of the estimation results, Chinese consumers' WTP amounts for various products awarded with China Environmental Label are found to be mainly determined by consumers' attitude towards tradeoff between environmental conservation and life convenience, consumers' belief in whether purchasing eco-labeled products is good for the environmental, and consumers' experience of purchasing eco-labeled products. With respect to the effect of socio-demographic characteristics on WTP amounts, gender, age, education and household income exhibit high significance in most of the cases.

In the following section we briefly describe the empirical model. The data and survey issue are described in Section 3. Results are presented in Section 4. Concluding remarks are provided in the last section.

\section{Empirical Model}

The interval data of WTP, which was elicited by a payment card method in our survey, can be analyzed by applying an Interval Regression model [17]. To motivate this model in our study, the respondent's true valuation or WTP is assumed to follow a linear function as given in Equation $(1)^{5}$.

$$
W T P_{i}=\alpha+x_{i}^{\prime} \beta+\varepsilon_{i}
$$

where $W T P_{i}$ is the latent WTP value of respondent $i$. $\alpha$ is the constant term. $x_{i}^{\prime}$ is a vector of explanatory variables that affect respondent $i$ 's willingness to pay for various eco-labeled products. $\beta$ is the parameter vector associated with $x_{i}^{\prime} . \varepsilon_{i}$ is the error term assumed to be normally distributed with mean zero and standard deviation $\sigma$. Then, by standardizing each pair of lower internal threshold $t_{l i}$ and upper internal threshold $t_{u i}$, the probability that the true valuation of WTP lies between both thresholds can be given as

$$
\begin{aligned}
& \operatorname{Pr}\left\{W T P_{i} \subseteq\left[t_{l i}, t_{u i}\right)\right\} \\
& =\operatorname{Pr}\left\{\frac{\left(t_{l i}-\alpha-x_{i}^{\prime} \beta\right.}{\sigma} \leq z_{i}<\frac{t_{u i}-\alpha-x_{i}^{\prime} \beta}{\sigma}\right\}
\end{aligned}
$$

where $z_{i}$ is the standard normal random variable. Consequently, the probability expressed in Equation (2) can be rewritten as the difference between two standard normal cumulative distributions functions and is expressed as

$$
\operatorname{Pr}\left\{W T P_{i} \subseteq\left[t_{l i}, t_{u i}\right)\right\}=\Phi\left(z_{u i}\right)-\Phi\left(z_{l i}\right)
$$

Finally, based on Equation (3), the log likelihood

${ }^{4}[18]$ applies Monte Carlo simulation and finds significant biases in the estimates, especially when the WTP function is assumed as the log-normal function.

${ }^{5}$ The respondent's WTP can also be assumed to follow a log-linear function if the WTP bids do not include zero. 
function is given as

$$
\log L=\sum_{i=1}^{N} \log \left[\Phi\left(z_{u i}\right)-\Phi\left(z_{l i}\right)\right]
$$

The maximum likelihood method is then applied in estimating Equation (4), which makes it possible to investigate the determinants of consumers' willingness to pay for eco-labeled products. Consequently, the mean and median WTP values for different eco-labeled products can be predicted by using the estimated parameters and the corresponding means and medians of the explanatory variables.

\section{Data}

We gathered data using a web-based survey. The survey was conducted by a professional marketing firm (Searchina Research) during October of 2007 in mainland China. To ensure that the questionnaire of the survey can be understood correctly by respondents, a pretest was conducted with the students from Shanghai Jiao Tong University. Some of their general comments and suggestions were then included in the final version of the survey.

At the beginning of the survey, respondents were randomly solicited via E-mails and asked for their voluntary participation in the survey. As a result, totally 1000 individuals covering each province of mainland China responded to the survey. Table 1 summarizes the sociodemographic characteristics of the sample. As shown in the table, $45.4 \%$ of the respondents were female, and the average age of the sample was about 30 years. $55.7 \%$ of the respondents had no child under 18 years old in their household, and majority of the respondents had college $(36 \%)$ or bachelor $(47.7 \%)$ degree. In addition, the mean household's monthly income was about 5000 - 5999 $\mathrm{RMB}$, and the average number of staffs in the respondents' company is about 100 - 499.

The questionnaire included three sections. In the first

Table 1. Variable definition and statistical description.

\begin{tabular}{|c|c|c|c|c|}
\hline Variable & \multicolumn{2}{|l|}{ Description } & Mean & S.D. \\
\hline Label_know & $\begin{array}{l}\text { Dummy variable, } 0=\text { the respondents do not know China Er } \\
1=\text { the respondents know China Environmental Label. }\end{array}$ & nvironmental Label, & 0.664 & 0.472 \\
\hline Label_believe & $\begin{array}{l}\text { Dummy variable, } 0=\text { the respondents do not believe purcha } \\
\text { for the environment, } 1=\text { the respondents believe purchasing } \\
\text { the environment. }\end{array}$ & $\begin{array}{l}\text { asing the eco-labeled products is good } \\
\mathrm{g} \text { the eco-labeled products is good for }\end{array}$ & 0.916 & 0.277 \\
\hline Envi_tradeoff & $\begin{array}{l}\text { Dummy variable, } 0=\text { the respondents favor life convenience } \\
\text { conservation, } 1=\text { the respondents favor environmental cons }\end{array}$ & $\begin{array}{l}\text { e more than environmental } \\
\text { ervation more than life convenience. }\end{array}$ & 0.750 & 0.433 \\
\hline Label_experience & $\begin{array}{l}\text { Dummy variable, } 0=\text { the respondents do not have the exp } \\
\text { products, } 1=\text { the respondents have the experience of purcha }\end{array}$ & $\begin{array}{l}\text { erience of purchasing the eco-labeled } \\
\text { asing the eco-labeled products. }\end{array}$ & 0.393 & 0.488 \\
\hline Age & Age of the respondents. & & 29.95 & 7.249 \\
\hline Children & Dummy variable, $0=$ no children under 18 years old, $1=$ ot & herwise & 0.443 & 0.497 \\
\hline Education & 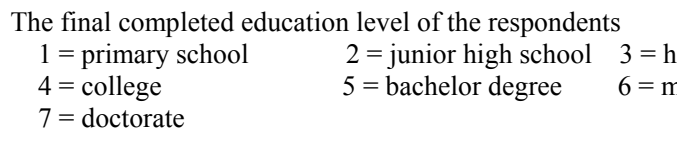 & $\begin{array}{l}\text { iigh school } \\
\text { naster degree }\end{array}$ & 4.411 & 0.795 \\
\hline Income & $\begin{array}{l}\text { Household's monthly income level of the respondents } \\
\begin{array}{l}1<2000 \mathrm{RMB} \\
\begin{array}{l}4=4000-4999 \mathrm{RMB} \\
7=7000-7999 \mathrm{RMB}\end{array} \quad 5=5000-5999 \mathrm{RMB} \\
10=10,000-14,999 \mathrm{RMB} \quad 11=15,000-19,999 \mathrm{RMB}\end{array}\end{array}$ & $\begin{array}{c}3=3000-3999 \mathrm{RMB} \\
6=6000-6999 \mathrm{RMB} \\
9=9000-9999 \mathrm{RMB} \\
12 \geq 20,000 \mathrm{RMB}\end{array}$ & 5.547 & 3.055 \\
\hline Staff_number & $\begin{array}{l}\text { Number of the staffs in the respondents' company } \\
\begin{aligned} 1=1-49 \text { staffs } & 2=50-99 \text { staffs } \\
4=500-999 \text { staffs } & 5 \geq 1000 \text { staffs }\end{aligned}\end{array}$ & $3=100-499$ staffs & 2.853 & 1.458 \\
\hline
\end{tabular}


section, we asked the respondents about their consideration on tradeoff between environmental conservation and life convenience, whether they knew China Environmental Label, whether they believe purchasing the eco-labeled products is good for the environment, and whether they have the experience of purchasing the eco-labeled products. The next 15 questions in the second section focused on eliciting the respondents' willingness to pay for the eco-labeled products. The questions were asked through "compared to the non-eco-labeled products, how much percentage you are willing to pay for the price up of the corresponding products awarded with China Envi-

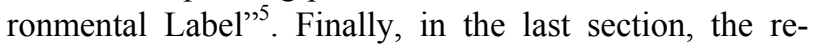
spondents were asked to answer the questions about their socio-demographic information such as gender, age, final completed education level, and net monthly household income.

\section{Results}

\subsection{Descriptive Analysis}

Tables 2(a)-(c) report the percentages of the WTP intervals for eco-labeled furniture, appliance, building material, glass tableware, recycled paper, battery, and soft drink chosen by the respondents. From the tables, we may observe that (i) for the bids larger than zero in all the product categories, a negative relationship can be found between the percentages and the WTP bid amounts, i.e., as the bids increase, the percentages decrease; and (ii) in the cases of furniture, appliance, building material and glass tableware, for the bid amount being zero, the percentages in the lower price are lower than those in the regular and higher price. It is noted that both observations do not surprise us because they are consistent with basic economic principle that demand negatively responds to price.

\subsection{Determinants of WTP Amounts}

Estimation results for the determinants affecting WTP for the seven eco-labeled products are presented in Tables 3(a) and (b), respectively. With respect to the variable referring to consideration on tradeoff between environmental conservation and life convenience (represented by Envi_tradeoff), it is significantly estimated with positive sign, implying that consumers who weigh environmental conservation more than life convenience are willing to pay more for all the seven eco-labeled products. In other words, consumers with higher environmental conscious-

\footnotetext{
${ }^{6} \mathrm{We}$ focused on seven eco-labeled product categories, i.e., furniture, appliance, building material, glass tableware, recycled paper, battery, and soft drink. In addition, for the previous four categories, we further divided them into three parts based on their price levels, i.e., higher price, regular price, and lower price (for definitions, see notes in Tables 2(a) and (b)).
}

ness tend to behave pro-environmentally. In addition, the variable of consumers having the experience of purchasing the eco-labeled products (reflected by Label_experience) is estimated with significant and positive sign in five of seven product categories (i.e., furniture, appliance, building material, glass tableware and recycled paper), suggesting that having the experience in purchasing the eco-labeled products is also an important factor affecting consumers' WTP for the environmental label. Furthermore, Label_believe reflecting the respondents who believe purchasing the eco-labeled products is good for the environment is estimated with significantly positive sign in furniture, appliance, recycled paper and soft drink. This evidence is plausible because if consumers do not believe green purchasing is good for the environment, it may be true that they will not be willing to pay extra money for pro-environmental products. Label_know is not significant in any cases, implying that having already known China Environmental Label is not relevant to consumers' WTP for eco-labeled products.

Concerning the issue of socio-demographic characterristics affecting consumers' WTP for eco-labeled products, age is estimated with significant and negative sign in all the products except recycled paper, suggesting that younger people in China are willing to pay more for ecolabeled products. In addition, the magnitude of this parameter implies that as consumers get one year older, they are less willing to pay $0.1 \%$ of the price for those eco-labeled products. The variable female is estimated with significantly negative sign in all the seven categories. This evidence is, in part, consistent with the result of [19] that in China men are more concerned about the environment than women. While it is opposite to several previous studies (e.g., [20] and [21]) and the "white male effect" found in US (e.g., [22] and [23]), the possible reasons for its happening have been provided in [19] which is stated that in China men are likely to be more altruistic, more politically active, and have relatively higher levels of education than women. In addition, income seems to be an important factor to determine the WTP amount for eco-labeled products because significant and positive sign of this variable is estimated in all the categories. This result suggests that consumers with higher household income are willing to pay more for eco-labeled products. Meanwhile, the variable of education is also found to be significantly and positively correlated with WTP values in four of the seven categories (i.e., appliance, building material, glass tableware and battery). Two other variables children and staff_number are not significant in any cases.

The effect of eco-labeled products' price level on WTP is also examined in four product categories (i.e., furniture, appliance, building material and glass tableware) and 

Analysis of the China Environmental Label

Table 2. (a) Percentages of WTP for the eco-labeled furniture and appliance.

\begin{tabular}{|c|c|c|c|c|c|c|}
\hline & \multicolumn{3}{|c|}{ Furniture } & \multicolumn{3}{|c|}{ Appliance } \\
\hline & Higher price $^{\mathrm{a}}$ & Regular price $^{\mathrm{b}}$ & Lower price $^{\mathrm{c}}$ & Higher price $^{\mathrm{d}}$ & Regular price $^{\mathrm{e}}$ & Lower price $^{f}$ \\
\hline $\mathrm{WTP}=0$ & 14.1 & 13.7 & 12.8 & 16.7 & 15.6 & 14.9 \\
\hline $\mathrm{WTP} \subset 0 \%-5 \%$ & 37.4 & 37.3 & 38.3 & 37.0 & 36.7 & 38.1 \\
\hline $\mathrm{WTP} \subset 6 \%-10 \%$ & 28.1 & 27.8 & 25.4 & 26.3 & 29.4 & 25.6 \\
\hline $\mathrm{WTP} \subset 11 \%-20 \%$ & 10.4 & 10.6 & 11.5 & 10.6 & 9.1 & 9.9 \\
\hline $\mathrm{WTP} \subset 21 \%-30 \%$ & 4.3 & 4.5 & 4.7 & 4.0 & 4.1 & 4.6 \\
\hline $\mathrm{WTP} \subset 31 \%-40 \%$ & 1.9 & 2.2 & 2.2 & 1.8 & 1.5 & 1.9 \\
\hline $\mathrm{WTP} \subset 41 \%-50 \%$ & 1.7 & 1.5 & 1.3 & 1.4 & 0.5 & 1.6 \\
\hline $\mathrm{WTP} \subset 51 \%-60 \%$ & 1.0 & 0.6 & 0.8 & 0.5 & 0.5 & 0.7 \\
\hline $\mathrm{WTP} \subset 61 \%-70 \%$ & 0.3 & 0.6 & 0.7 & 0.4 & 1.2 & 0.6 \\
\hline $\mathrm{WTP} \subset 71 \%-80 \%$ & 0.3 & 0.4 & 0.7 & 0.4 & 0.7 & 0.6 \\
\hline $\mathrm{WTP} \subset 81 \%-90 \%$ & 0.2 & 0.3 & 0.7 & 0.6 & 0.3 & 0.6 \\
\hline $\mathrm{WTP} \subset 91 \%-100 \%$ & 0.2 & 0.3 & 0.4 & 0.2 & 0.2 & 0.5 \\
\hline $\mathrm{WTP}>100 \%$ & 0.1 & 0.2 & 0.5 & 0.1 & 0.2 & 0.4 \\
\hline
\end{tabular}

${ }_{\mathrm{a}, \mathrm{d}}$ denotes price $>4000$ RMB. ${ }^{\mathrm{b}, \mathrm{e}}$ denotes price $\subset 2000-4000$ RMB. ${ }^{\mathrm{c}, \mathrm{f}}$ denotes price $<2000$ RMB.

Table 2. (b) Percentages of WTP for the eco-labeled building material and glass tableware.

\begin{tabular}{|c|c|c|c|c|c|c|}
\hline & \multicolumn{3}{|c|}{ Building material } & \multicolumn{3}{|c|}{ Glass tableware } \\
\hline & Higher price $^{\mathrm{a}}$ & Regular price $^{\mathrm{b}}$ & Lower price $^{\mathrm{c}}$ & Higher price $^{\mathrm{d}}$ & Regular price $^{\mathrm{e}}$ & Lower price $^{f}$ \\
\hline $\mathrm{WTP}=0$ & 17.8 & 16.6 & 15.2 & 22.0 & 22.2 & 20.1 \\
\hline $\mathrm{WTP} \subset 0 \%-5 \%$ & 34.8 & 37.7 & 39.4 & 38.6 & 37.9 & 35.0 \\
\hline $\mathrm{WTP} \subset 6 \%-10 \%$ & 23.6 & 25.2 & 23.8 & 22.7 & 22.0 & 23.2 \\
\hline $\mathrm{WTP} \subset 11 \%-20 \%$ & 11.5 & 9.9 & 9.5 & 7.3 & 8.0 & 9.6 \\
\hline $\mathrm{WTP} \subset 21 \%-30 \%$ & 5.5 & 4.0 & 4.9 & 3.6 & 3.5 & 3.9 \\
\hline $\mathrm{WTP} \subset 31 \%-40 \%$ & 2.8 & 1.9 & 1.9 & 1.9 & 1.6 & 2.2 \\
\hline $\mathrm{WTP} \subset 41 \%-50 \%$ & 1.2 & 1.3 & 1.3 & 1.3 & 1.1 & 2.0 \\
\hline $\mathrm{WTP} \subset 51 \%-60 \%$ & 1.2 & 1.4 & 1.1 & 0.9 & 1.2 & 0.9 \\
\hline $\mathrm{WTP} \subset 61 \%-70 \%$ & 0.3 & 0.5 & 0.6 & 0.6 & 0.8 & 0.7 \\
\hline $\mathrm{WTP} \subset 71 \%-80 \%$ & 0.6 & 0.7 & 0.6 & 0.4 & 0.8 & 0.7 \\
\hline $\mathrm{WTP} \subset 81 \%-90 \%$ & 0.3 & 0.4 & 0.6 & 0.3 & 0.5 & 0.6 \\
\hline $\mathrm{WTP} \subset 91 \%-100 \%$ & 0.2 & 0.1 & 0.5 & 0.2 & 0.2 & 0.6 \\
\hline WTP > 100\% & 0.2 & 0.3 & 0.6 & 0.2 & 0.2 & 0.5 \\
\hline
\end{tabular}

${ }^{\mathrm{a}}$ denotes price $>40,000 \mathrm{RMB} .{ }^{\mathrm{b}}$ denotes price $\subset 20,000-40,000 \mathrm{RMB}$. ${ }^{\mathrm{C}}$ denotes price $<20,000 \mathrm{RMB}$; ${ }^{\mathrm{d}}$ denotes price $>1000$ RMB. ${ }^{\mathrm{e}} \mathrm{denotes}$ price $\subset 300-$ 1000 RMB. ${ }^{\mathrm{f}}$ denotes price $<300 \mathrm{RMB}$.

Table 2. (c) Percentages of WTP for the eco-labeled recycled paper, battery and soft drink.

\begin{tabular}{cccc}
\hline & Recycled paper & Battery & Soft drink \\
\hline WTP $=0$ & 20.5 & 19.1 & 23.4 \\
WTP $\subset 0 \%-5 \%$ & 37.4 & 37.4 & 37.3 \\
WTP $\subset 6 \%-10 \%$ & 20.6 & 20.4 & 18.2 \\
WTP $\subset 11 \%-20 \%$ & 9.2 & 9.5 & 8.2 \\
WTP $\subset 21 \%-30 \%$ & 4.5 & 4.2 & 4.5 \\
WTP $\subset 31 \%-40 \%$ & 2.4 & 2.1 & 1.5 \\
WTP $\subset 41 \%-50 \%$ & 1.4 & 1.6 & 1.5 \\
WTP $\subset 51 \%-60 \%$ & 1.1 & 1.5 & 1.4 \\
WTP $\subset 61 \%-70 \%$ & 0.8 & 1.1 & 1.2 \\
WTP $\subset 71 \%-80 \%$ & 0.6 & 0.9 & 1.0 \\
WTP $\subset 81 \%-90 \%$ & 0.5 & 0.8 & 0.6 \\
WTP $\subset 91 \%-100 \%$ & 0.5 & 0.7 & 0.6 \\
WTP $>100 \%$ & 0.4 & 0.7 & 0.6 \\
\hline
\end{tabular}


Table 3. (a) Determinants of WTP for the eco-labeled furniture, appliance, building material and glass tableware.

\begin{tabular}{ccccc}
\hline & Furniture & Appliance & Building material & Glass tableware \\
\hline Constant & $0.091(3.58)^{* * *}$ & $0.121(4.67)^{* * *}$ & $0.143(5.54)^{* * *}$ & $0.077(2.77)^{* * *}$ \\
Label_know & $-0.016(1.30)$ & $-0.020(1.07)$ & $-0.007(1.02)$ & $-0.012(1.29)$ \\
Label_believe & $0.028(3.71)^{* * *}$ & $0.023(2.75)^{* * *}$ & $0.009(1.01)$ & $0.006(0.62)$ \\
Envi_tradeoff & $0.025(4.31)^{* * *}$ & $0.028(4.82)^{* * *}$ & $0.020(3.33)^{* * *}$ & $0.024(4.00)^{* * *}$ \\
Label_experience & $0.015(2.52)^{* *}$ & $0.021(3.61)^{* * *}$ & $0.014(2.10)^{* *}$ & $0.012(1.96)^{* *}$ \\
Female & $-0.013(2.27)^{* *}$ & $-0.007(2.28)^{* *}$ & $-0.008(2.19)^{* *}$ & $-0.005(1.81)^{* *}$ \\
Age & $-0.001(2.66)^{* * *}$ & $-0.001(3.65)^{* * *}$ & $-0.002(3.69)^{* * *}$ & $-0.001(3.16)^{* * *}$ \\
Children & $-0.005(0.78)$ & $-0.008(1.26)$ & $-0.004(0.70)$ & $-0.007(1.04)$ \\
Education & $0.003(0.86)$ & $0.006(1.68)^{*}$ & $0.008(2.08)^{* *}$ & $0.004(2.21)^{* *}$ \\
Income & $0.004(3.88)^{* * *}$ & $0.002(1.79)^{*}$ & $0.002(2.49)^{* *}$ & $0.004(3.54)^{* * *}$ \\
Staff_number & $0.003(1.60)$ & $0.001(0.83)$ & $0.001(0.42)$ & $0.002(0.90)$ \\
High price & $-0.012(1.76)^{*}$ & $-0.007(1.16)$ & $-0.008(2.15)^{* *}$ & $-0.014(2.08)^{* *}$ \\
Regular price & $-0.008(1.22)$ & $-0.006(0.94)$ & $-0.005(0.76)$ & $-0.008(1.14)$ \\
Sigma & $0.143^{* * *}$ & $0.140^{* * *}$ & $0.147^{* * *}$ & $0.148^{* * *}$ \\
Log-likelihood & -6059.36 & -5853.15 & -5930.88 & 3000 \\
Observations & 3000 & 3000 & -5464.48
\end{tabular}

Absolute robust $\mathrm{z}$ statistics are in parentheses. *significant at $10 \%, * *$ significant at $5 \%, * * *$ significant at $1 \%$.

Table 3. (b) Determinants of WTP for the eco-labeled recycled paper, battery and soft drink.

\begin{tabular}{cccc}
\hline & Recycled paper & Battery & Soft drink \\
\hline Constant & $0.027(0.59)$ & $0.068(1.66)^{*}$ & $0.082(1.88)^{*}$ \\
Label_know & $-0.014(1.33)$ & $-0.008(0.65)$ & $-0.013(1.07)$ \\
Label_believe & $0.008(2.43)^{* *}$ & $-0.010(0.51)$ & $0.009(1.76)^{*}$ \\
Envi_tradeoff & $0.014(2.39)^{* *}$ & $0.023(2.16)^{* *}$ & $0.026(2.44)^{* *}$ \\
Label_experience & $0.022(2.18)^{* *}$ & $0.016(1.36)$ & $0.014(1.16)$ \\
Female & $-0.016(1.67)^{*}$ & $-0.019(1.82)^{*}$ & $-0.021(2.08)^{* *}$ \\
Age & $-0.0003(0.40)$ & $-0.001(2.00)^{* *}$ & $-0.001(2.01)^{* *}$ \\
Children & $-0.001(0.07)$ & $-0.003(0.25)$ & $0.0005(0.04)$ \\
Education & $0.009(1.51)$ & $0.010(1.65)^{*}$ & $0.005(0.82)$ \\
Income & $0.004(2.60)^{* * *}$ & $0.002(1.89)^{*}$ & $0.003(1.87)^{*}$ \\
Staff_number & $-0.001(0.42)$ & $-0.002(0.74)$ & $-0.002(0.67)$ \\
Sigma & $0.145^{* * *}$ & $0.153^{* * *}$ & $0.153^{* * *}$ \\
Log-likelihood & -1870.25 & -1986.48 & -1861.58 \\
Observations & 1000 & 1000 & 1000
\end{tabular}

Absolute robust $z$ statistics are in parentheses. *significant at $10 \%, * *$ significant at $5 \%, * * *$ significant at $1 \%$.

presented in Table 3(a). The variable higher price is significantly estimated with negative sign in three products, while the variable regular price is not statistically significant in any products. These results indicate that when facing products with relatively higher price, consumers' willingness to pay for the eco-label would be reduced. It is thought to be plausible because purchasing products with relatively higher price means a relatively larger capital expense to consumers, which leads to the risk associated with an incorrect decision being high. Therefore, if the consumers are risk-averse, they are clearly less willing to pay more for eco-labeled products with higher price level.

\subsection{Comparing among Mean WTP Estimates}

Mean WTP estimates for the seven eco-labeled products are presented in the second row of Table 4 . These values 
Analysis of the China Environmental Label

Table 4. Mean WTP estimates and Wilcoxon signed-rank tests.

\begin{tabular}{|c|c|c|c|c|c|c|c|}
\hline & Furniture & Appliance & $\begin{array}{l}\text { Building } \\
\text { material }\end{array}$ & $\begin{array}{c}\text { Glass } \\
\text { tableware }\end{array}$ & $\begin{array}{l}\text { Recycled } \\
\text { paper }\end{array}$ & Battery & $\begin{array}{r}\text { Soft } \\
\text { drink }\end{array}$ \\
\hline Mean WTP & 9.46 & 9.00 & 9.51 & 8.71 & 8.77 & 9.46 & 8.78 \\
\hline Furniture & - & & & & & & \\
\hline Appliance & $24.24 * * *$ & - & & & & & \\
\hline Building material & -0.91 & $-31.58 * * *$ & - & & & & \\
\hline Glass tableware & $34.70 * * *$ & $12.28 * * *$ & $29.49 * * *$ & - & & & \\
\hline Recycled paper & $4.06^{* * *}$ & $-2.10^{* *}$ & $3.19 * * *$ & $-3.08 * * *$ & - & & \\
\hline Battery & $-2.61 * * *$ & $-9.09 * * *$ & $-4.42 * * *$ & $-9.93 * * *$ & $-18.22 * * *$ & - & \\
\hline Soft drink & $4.00^{* * *}$ & $-2.27 * *$ & $3.06^{* * *}$ & $-3.21 * * *$ & -0.90 & $20.66 * * *$ & - \\
\hline
\end{tabular}

*significant at $10 \%, * *$ significant at $5 \%, * * *$ significant at $1 \%$.

are evaluated by the estimated parameters presented in Tables 3(a) and (b) and means of the corresponding explanatory variables. We find that Chinese consumers are willing to pay $8.71 \%-9.51 \%$ in average for the corresponding products awarded with China Environmental Label. With respect to comparisons of mean WTPs for different kinds of products, a non-parametric Wilcoxon signed-rank test [24] is applied to test the hypothesis whether any pair of mean WTP is equal. Results presented in Table 4 indicate that all the pairs of mean WTP values except two (i.e., furniture vs building material and recycled paper vs soft drink) are significantly different at a high significance level, suggesting that the percentage of willingness to pay extra money for different eco-labeled products varies among products ${ }^{7}$.

\section{Conclusions}

In this study we apply data from a web-based survey conducted in China to examine the determinants of consumers' WTP for seven different product categories awarded with China Environmental Label and compare the mean WTP estimates among these categories. Interval regression results indicate that Chinese consumers who regard environmental conservation as being more important than life convenience, who believe purchasing the eco-labeled products is good for the environment, and who have the experience in purchasing eco-labeled products are willing to pay more for those products with environmental label. In addition, socio-demographic characteristics such as gender, age, education and income are found to be important factors to affect Chinese consumers' WTP amounts.

The results of pair-wise comparison among the mean WTP estimates of various eco-labeled products indicate

\footnotetext{
${ }^{7}$ There may be the case that the absolute WTP value is different but the percentage of WTP is the same. Thus, in this sense the evidence that the differences in the percentages of WTP for various products labeled with China Environmental Label found in the present study is a relatively stronger result.
}

that most of them are different, which implies that the degrees of Chinese consumers' willingness to pay extra money for China Environmental Label are different based on the types of products. This result is not surprising to us because consumers usually evaluate variant products differently. However, it is considered to be important to both environmental policy decision makers and producers. For the decision makers, because consumers prefer to pay extra money for environmentally friendly products, thus, it is worthy of considering enlarging the range of products awarded with environmental label. For the producers, it may create both incentives to invest in green production technology and adjust the prices of their eco-labeled prices as a marketing strategy to meet consumers' needs.

Finally, the present study is suggestive of two areas for continued research. First, the results and findings are based on consumers in China. Therefore, future studies targeting on consumers in other countries are encouraged to make international comparisons on the issue of the determinants of consumers' WTP for eco-labeled products and help ensure the validity of these findings. Second, attributes of products, which may also be important in determining the WTP amount, are not included in the present study due to the difficult in survey design. We leave this issue as an open question and expect a great effort to investigate it in future studies.

\section{REFERENCES}

[1] J. Shen and T. Saijo, "Does Energy Efficiency Label Alter Consumers' Purchase Decision? A Latent Class Approach on Shanghai Data," Journal of Environmental Management, Vol. 90, No. 11, 2009, pp. 3561-3573. doi:10.1016/j.jenvman.2009.06.010

[2] I. G. Gallastegui, "The Use of Eco-Labels: A Review of the Literature," European Environment, Vol. 12, No. 6, 2002, pp. 316-331. doi:10.1002/eet.304

[3] M. F. Teisl, C. L. Noblet and J. Rubin, "The Design of an Eco-Marketing and Labeling Program for Vehicles," In: 
U. Grote, A. K. Basu and N. H. Chau, Eds., New Frontiers in Environmental and Social Labeling, PhysicaVerlag Press, Heidelberg, 2007.

doi:10.1007/978-3-7908-1756-0 2

[4] A. K. Basu, N. H. Chau and U. Grote, "Eco-Labeling and Stages of Development," Review of Development Economics, Vol. 7, No. 2, 2003, pp. 228-247. doi:10.1111/1467-9361.00188

[5] T. B. Bjørner, L. G. Hansen and C. R. Russell, "Environmental Labeling and Consumers' Choice-An Empirical Analysis of the Effect of the Nordic Swan," Journal of Environmental Economics and Management, Vol. 47, No. 3, 2004, pp. 411-434. doi:10.1016/j.jeem.2003.06.002

[6] T. N. Cason and L. Gangadharan, "Environmental Labeling and Incomplete Consumer Information in Laboratory Markets," Journal of Environmental Economics and Management, Vol. 43, No. 1, 2002, pp. 113-134. doi:10.1006/jeem.2000.1170

[7] R. J. Johnston, C. R. Wessells, H. Donath and F. Asche, "Measuring Consumer Preferences for Ecolabeled Seafood: An International Comparison," Journal of Agricultural and Resource Economics, Vol. 26, No. 1, 2001, pp. 20-39.

[8] M. L. Loureiro and S. Hine, "Discovering Niche Markets: A Comparison If Consumer Willingness to Pay for Local (Colorado Grown), Organic, and GMO-Free Products," Journal of Agricultural and Applied Economics, Vol. 34, No. 2, 2002, pp. 477-487.

[9] M. L. Loureiro, J. J. McCluskey and R. C. Mittelhammer, "Will Consumers Pay a Premium for Eco-Labeled Apples?" Journal of Consumer Affairs, Vol. 36, No. 2, 2002 , pp. 203-219. doi:10.1111/j.1745-6606.2002.tb00430.x

[10] W. Moon, W. J. Florkowski, B. Brückner and I. Schonhof, "Willingness to Pay for Environmental Practices: Implications for Eco-Labeling," Land Economics, Vol. 78, No. 1, 2002, pp. 88-102. doi:10.2307/3146925

[11] B. Roe, M. F. Teisl, A. Levy and M. Russell, "US Consumers' Willingness to Pay for Green Electricity," Energy Policy, Vol. 29, No. 11, 2001, pp. 917-925. doi:10.1016/S0301-4215(01)00006-4

[12] G. Grankvist and A. Biel, "The Importance of Beliefs and Purchase Criteria in the Choice of Eco-Labeled Food Products," Journal of Environmental Psychology, Vol. 21, No. 3, 2001, pp. 405-410. doi:10.1006/jevp.2001.0234

[13] J. A. Lee and S. J. S. Holden, "Understanding the Determinants of Environmentally Conscious Behavior," Psychology and Marketing, Vol. 16, No. 5, 1999, pp. 373-
392.

doi:10.1002/(SICI)1520-6793(199908)16:5<373::AID-M AR1>3.0.CO;2-S

[14] P. C. Stern, "Toward a Coherent Theory of Environmentally Significant Behavior," Journal of Consumer policy, Vol. 22, 2000, pp. 461-478. doi:10.1023/A:1006211709570

[15] J. Thøgersen, "Psychological Determinants of Paying Attention to Eco-Labels in Purchase Decisions: Model Development and Multinational Validation," Journal of Consumer Policy, Vol. 23, No. 3, 2000, pp. 285-313. doi:10.1023/A:1007122319675

[16] R. C. Mitchell and R. T. Carson, "Using Surveys to Value Public Goods: the Contingent Valuation Method," Resources for the Future, Washington D.C., 1989.

[17] J. M. Wooldridge, "Econometric Analysis of Cross Section and Panel Data," The MIT Press, Massachusetts, 2002.

[18] T. A. Cameron, "The Impact of Grouping Coarseness in Alternative Grouped-Data Regression Models," Journal of Econometrics, Vol. 35, No. 1, 1987, pp. 37-57. doi:10.1016/0304-4076(87)90080-7

[19] J. Shen and T. Saijo, "Reexamining the Relations between Socio-Demographic Characteristics and Individual Environmental Concern: Evidence from Shanghai Data," Journal of Environmental Psychology, Vol. 28, No. 1, 2008, pp. 42-50. doi:10.1016/j.jenvp.2007.10.003

[20] L. M. Hunter, A. Hatch and A. Johnson, "Cross-National Gender Variation in Environmental Behaviors," Social Science Quarterly, Vol. 85, No. 3, 2004, pp. 677-694. doi:10.1111/j.0038-4941.2004.00239.x

[21] P. Mohai, "Men, Women and the Environment: An Examination of the Gender Gap in Environmental Concern Activism," Society and Natural Resources, Vol. 5, No. 1, 1992, pp. 1-19. doi:10.1080/08941929209380772

[22] M. L. Finucane, P. Slovis, C. K. Mertz, J. Flynn and T. A. Satterfield, "Gender, Race, and Perceived Risk: The 'White Male' Effect," Health, Risk \& Society, Vol. 2, No. 2, 2000, pp. 159-172. doi:10.1080/713670162

[23] J. Flynn, P. Slovic and C. K. Mertz, "Gender, Race, and Perception of Environmental Health Risks," Risk Analysis, Vol. 14, No. 4, 1994, pp. 1101-1108. doi:10.1111/j.1539-6924.1994.tb00082.x

[24] F. Wilcoxon, "Individual Comparisons by Ranking Methods," Biometrics, Vol. 1, No. 6, 1945, pp. 80-83. doi: $10.2307 / 3001968$ 